\title{
Tracing physical movement during practice-based learning through Multimodal Learning Analytics
}

\author{
Donal Healion \\ National College of Art \& \\ Design, Dublin \\ Dublin, Ireland \\ healiond@staff.ncad.ie \\ russells@staff.ncad.ie
}

\author{
Mutlu Cukurova \\ UCL Knowledge Lab \\ University College London, \\ United Kingdom
}

\author{
Daniel Spikol \\ Malmö University \\ Malmö, \\ Sweden
}

m.cukurova@ucl.ac.uk daniel.spikol@mah.se

\begin{abstract}
In this paper, we pose the question, can the tracking and analysis of the physical movements of students and teachers within a PracticeBased Learning (PBL) environment reveal information about the learning process that is relevant and informative to Learning Analytics (LA) implementations? Using the example of trials conducted in the design of a LA system, we aim to show how the analysis of physical movement from a macro level can help to enrich our understanding of what is happening in the classroom. The results suggest that Multimodal Learning Analytics (MMLA) could be used to generate valuable information about the human factors of the collaborative learning process and we propose how this information could assist in the provision of relevant supports for small group work. More research is needed to confirm the initial findings with larger sample sizes and refine the data capture and analysis methodology to allow automation.
\end{abstract}

\section{CCS Concepts}

- Applied computing Interactive learning environments

- Applied computing Collaborative learning

- Information systems $\sim$ Data analytics

\section{Keywords}

Practice-based learning; collaborative problem solving; collaborative learning environment; learning analytics; movement.

\section{INTRODUCTION}

This paper discusses the exploration of physical movement by both students and teachers while engaged in Collaborative Problem Solving (CPS) during PBL activities. Using data gathered from multimodal sources, we examine the movements of students and teachers that occur within the learning environment, to gain information about the physical nature of collaborative group work. Our research question is how can students' and teachers' movement around the furniture be used to gain a better understanding of students collaborative learning processes? For the purposes of this paper, the movements analysed are at the macro level (i.e. within the classroom space). These movements are tracked via a range of multimodal sensing devices with analysis carried out by a mixture between human and machine coding. The intent of this research is to use an enhanced understanding of the collaborative learning process to inform the development of LA implementations.

\footnotetext{
Permission to make digital or hard copies of part or all of this work for personal or classroom use is granted without fee provided that copies are not made or distributed for profit or commercial advantage and that copies bear this notice and the full citation on the first page. Copyrights for thirdparty components of this work must be honored. For all other uses, contact the Owner/Author. Copyright is held by the owner/author(s).

LAK '17, March 13-17, 2017, Vancouver, BC, Canada ACM 978-1-4503-4870-6/17/03.

http://dx.doi.org/10.1145/3027385.3029474
}

\section{BACKGROUND}

The work described in this paper has been carried out as part of the Practice-based Experiential Learning Analytics Research and Support (PELARS) project, a three year, EU funded FP7 research and design project that seeks to create a Learning Analytics System (LAS) suitable for implementation in the teaching of PBL activities in three learning contexts, secondary Science, Technology, Engineering and Mathematics (STEM) subjects, third level interaction design and third level engineering education. The project seeks to understand how students learn while engaged in open-ended CPS in PBL activities in these scenarios [1]. The LAS is designed to achieve this through the aggregation and analysis of various multimodal data streams generated by sensing technologies embedded in the learning environment (video, audio, still image capture and data log files) and user generated data (via "sentiment" feedback buttons and a mobile application).

\section{METHODOLOGY}

Outlined below are two trials carried out during cycles of iterative prototyping, trials and evaluation established within the PELARS project to test the LAS and associated learning environment "in the wild" and incorporate user feedback into subsequent design iterations.

The hypothesis of the first trial is that students engaged in a PBL task at standing height tables would physically move more than those seated at standard height tables and that these movements would give rise to more interactions with their peers. Six table tops of various shapes were produced with one table top of each shape mounted at $770 \mathrm{~mm}$ (sitting height) and one at $1,020 \mathrm{~mm}$ (standing height). Table 1 in the results section shows the trial findings.

The purpose of the second trial (along with testing the LAS) was to record the movement and interactions of students engaged in a PBL task at specially designed standing tables with circular table tops to allow comparison with those of their peers seated at standard height rectangular tables. It further sought to track the movements and interactions of the teachers/facilitators during the activity. Two sample spaghetti diagrams visualising the movements of a student and a facilitator during this trial are shown in the results section. Both of these trials were conducted in a classroom type environment with randomised groups of three and four, mixed gender, secondary school-level students.

\section{RESULTS}

Table 1 below shows the results from Trial 1. It details the number of movements away from the appointed table, interactions with other students, number of interventions by four facilitators at each table and number of times the students reform at the table in the same or different configurations. The figures shown in the rows for each table are the aggregated totals for each of the three students at that table. 
Table 1. Movements and interactions during Trial 1

\begin{tabular}{|c|c|c|c|c|c|c|}
\hline $\begin{array}{l}\dot{0} \\
\frac{0}{0} \\
\stackrel{0}{0}\end{array}$ & 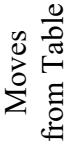 & 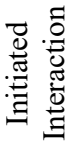 & 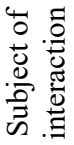 & 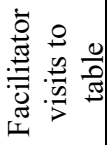 & 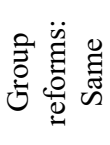 & 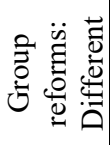 \\
\hline HTR & 37 & 8 & 8 & 19 & 5 & 23 \\
\hline HTH & 39 & 9 & 1 & 18 & 4 & 17 \\
\hline HTS & 12 & 2 & 2 & 19 & 7 & 5 \\
\hline LTR & 4 & 2 & 6 & 19 & 0 & 1 \\
\hline $\mathrm{LTH}$ & 1 & 0 & 5 & 24 & 0 & 0 \\
\hline LTS & 9 & 9 & 1 & 23 & 0 & 0 \\
\hline
\end{tabular}

HTR $=$ High Table Round, HTH $=$ High Table Hexagonal,

HTS $=$ High Table Square, LTR $=$ Low Table Round,

LTH $=$ Low Table Hexagonal, LTS $=$ Low Table Square

The diagrams below were generated from data collected in Trial 2 to show the greatest amount of student movement (Fig. 1 Student 5) and movements of the main facilitator (Fig. 2 Facilitator 1). Each line represents a return movement for the subject involved unless an onward movement is indicated.

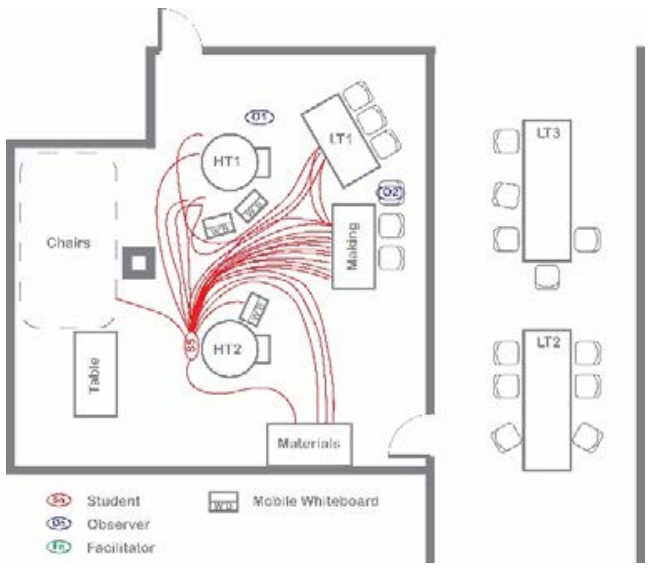

Figure 1. Spaghetti diagram showing the movements of Student 5 during Trial 2

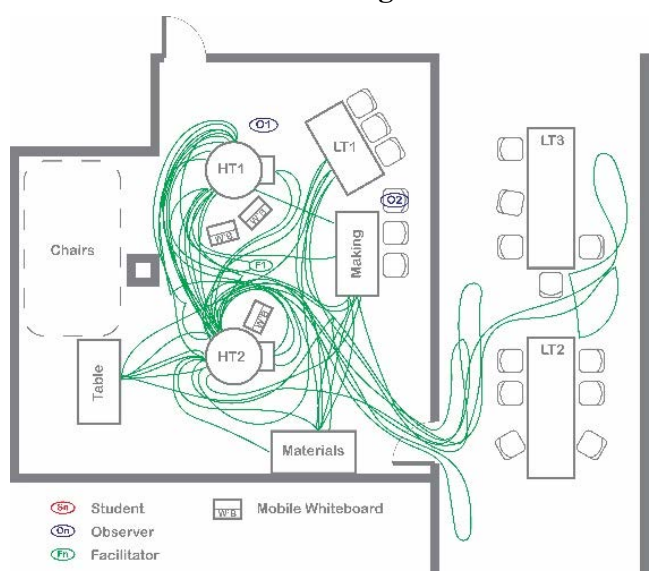

Figure 2. Spaghetti diagram showing the movements of Facilitator 1 during Trial 2

\section{DISCUSSION}

Collaboration is a "coordinated, synchronous activity that is the result of a continued attempt to construct and maintain a shared conception of a problem" [3] (p.70). It is a complex learning process that requires certain conditions to be satisfied for its success. These include shared goals, discussions and negotiations for accommodating others' perspectives and organised actions to reach a more desirable state from a problem state [2]. However, the fundamental condition for collaboration is the social interaction of students. Not all social interactions lead to collaboration, but all collaboration is a product of social interaction. Hence, in this paper, we investigated different furniture designs using a MMLA system and established that different furniture designs lead to varied levels of social interaction. Our results show that standing height hexagonal and round tables lead to more movements and social interactions between students compared to sitting height and square tables. Given the small sample size, varying contexts and participant student profiles of the trials, more research is required to confirm results and expand on this current work. However, the outcome of this exploration points towards the importance of the consideration of human factors in the design of learning environments and the LA technology that is implemented within it. The results confirm our hypothesis that the physical form of a workstation design has a bearing on group formation and dynamics. In this paper, we show that the design of furniture elements within the learning environment has an effect on the number of movements and interactions between the student groups. Of significance to LA design is that in order to acquire as complete a data set as possible, adequate resources for the PBL activity need to be supplied within the range of the LAS sensors or the sensing technology should have the capability to "follow" the student when away from the appointed workstation. These findings point to meaningful information to help researchers, teachers and learners understand, through the use of MMLA, what is happening in the classroom while engaged in CPS in PBL activities. Further work is required to validate these initial findings with larger sample sizes and to refine the data analysis process through automation.

\section{ACKNOWLEDGMENTS}

This work is co-funded by the European Union under the PELARS project (Grant Agreement \# 619738) under the Seventh Framework Programme of the European Commission.

\section{REFERENCES}

[1] Cukurova, M., Avramides, K., Spikol, D., Luckin, R. \& Mavrikis, M. 2016. An analysis framework for collaborative problem solving in practice-based learning activities: a mixed-method approach. In Proc. of the Sixth Int. Conf. on Learning Analytics \& Knowledge (LAK '16). 84-88. ACM, New York, NY, USA. http://dx.doi.org/10.1145/2883851.2883900

[2] Roschelle, J., \& Teasley, S. D. 1995. The construction of shared knowledge in collaborative problem-solving. In C. E. O'Malley (Ed.), Computer-supported collaborative learning. 69-97. Berlin: Springer-Verlag.

[3] OECD. 2015. Draft Collaborative Problem Solving Framework. Retrieved from: http://www.oecd.org/pisa/pisaproducts/Draft PISA 2015 Collaborative Problem Solving Framework.pdf 